\title{
Tourism Development and Impact on the Environment in the Region of Attica
}

\author{
Agisilaos Economou $^{1}$ and Roido Mitoula ${ }^{2}$ \\ ${ }^{1} \mathrm{PhD}$ National Technical University of Athens, Environmentalist \\ ${ }^{2}$ Professor, Harokopio University
}

\begin{abstract}
The Attica region has remarkable natural and cultural resources. In recent decades, many infrastructure projects have also been implemented through Community Framework Programs, which have contributed to improving the quality of life of residents and the development of the area. However, the region faces various economic problems due to the country's large public debt, but also environmental problems due to the intensity of human activities, which threaten to degrade its natural resources

The survey refers to the tourist development of the area and its impact on the environment. In particular, it focuses on infrastructure projects, tourism, hotel potential, cultural and natural environments, at impacts on natural resources and on policies implemented taking into account European Union directives on sustainable development.

Statistical data, legislative texts, geographic data and previous surveys were used to carry out the survey. A local sampling was also carried out in municipalities to identify the problems they are facing and the policies they have implemented to address them.

The survey has shown that tourism in the Attica region is of great importance for the economic development of the region, especially in recent years, due to the economic problems that exist in the country. Despite the policies that have been implemented, both for development and for the protection of the environment, the measures are not sufficient. New measures both to stimulate the tourism sector and other sectors are necessary.
\end{abstract}

Keywords: Tourism development, impact of the environment, Attica

\section{Introduction}

For years it has been established that the European coastal zone is highly populated. 130 million inhabitants out of the 350 million of the 18 Mediterranean countries, live on the coast.

This accumulation of population in the coastal zone can be attributed to the pursuit of economic opportunities, recreation and the pleasant climate. This phenomenon is greater in the Mediterranean countries, where it still has high tourist development. The number of tourists from 58 million in 1970 to 117 million in the mid-1980s [1] is expected to reach 195-217 million by 2025 [2].

The long-term future and viability of a tourist area depends on whether it provides tourists with an acceptable natural and urban environment. Continuous tourism development with simultaneous degradation of natural resources will lead to a reduction in the income of local residents. Also, when it comes to reducing trade, it is very difficult to reverse overbuilding that has already begun.

In order to address the above problems, the European Union has adopted several directives on the protection of natural resources and at the same time has funded through the Community support frameworks many projects to improve infrastructure and enhance tourism development,

Attica is an area as we will show below, that despite great urban development and problems, it has a particular interest due to the remarkable cultural and natural resources that presents. 


\section{Methodology}

Initially, research focuses on the importance of the region, its natural and cultural resources, tourism development, tourism, and then focuses on the problems. In this study, a sampling survey was conducted in the Municipalities of Attica. In addition to this, a methodology of personal interviews with managers of the municipality and a survey in situ in order to identify problems, have taken place. Statistical data and land use topography were also used. Data processing was done with the help of Geographic Information Systems.

\section{Case Study}

The Attica region is located in the center of Greece and has an area of 3,808. Km2, It covers $2.9 \%$ of the total area of the country (Fig 1).

It is surrounded by the South Evian Gulf in the east, and the Saronic Gulf in the south and southwest and the Corinthian Gulf and the Bay of Alkionides in the west. The region of Attica includes the islands of Aegina, Salamina, Agistri, Poros, Hydra, Spetses, Kythira and the area of Troizina - Methana in the Peloponnese.

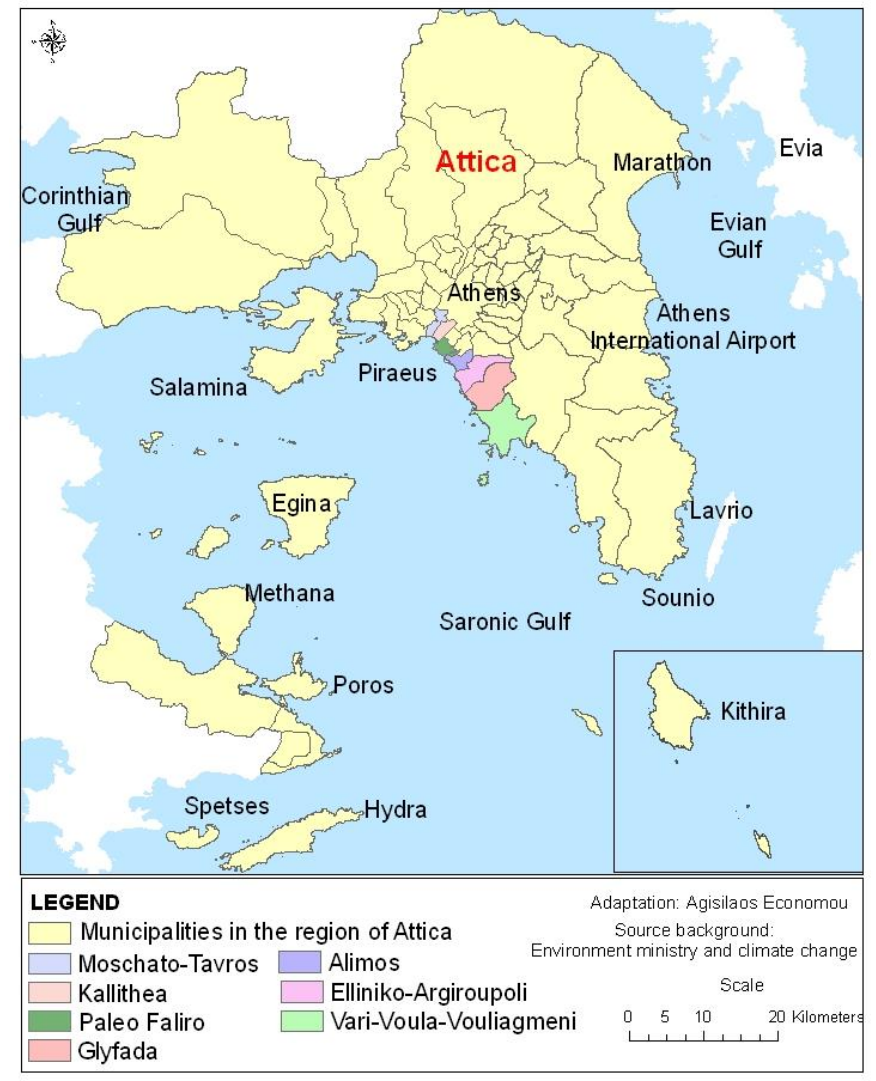

Fig 1. Municipalities in the region of Attica

\subsection{The importance of the Area}

The region of Attica has a great importance such as:

- Attica is known as the global cradle of culture, the area where the Republic was born and ancient Greek philosophy was developed, a area with a brilliant past (Pericles' Golden Age 5 century B.C.). It is the area where the great Greek Philosophers, Socrates, Plato, Aristotle, lived and had great influence and still have on all kinds of science at a global level.

- Ancient theater where tragedies, comedies' and poetry (Aeschylus, Euripides and Sophocles) flourished in the area of Attica.

- Also great battles took place in Attica (Marathon Battle, Battle of Salamis) that have played an important role in the further evolution of Europe. 
- Its weather conditions are excellent. Mild and wet winters and relatively hot and dry summers, high sunshine and average annual temperature from $16^{\circ} \mathrm{C}$ to $18{ }^{\circ} \mathrm{C}[3]$.

- The Attica region has remarkable natural resources such as the Mesogeion plain and the plain of Marathon.

- It has a great biodiversity. Many areas are included in the European Union lists as Special Natural Landscapes (20), Corine Biotopes (24), Natura 2000 (8), National Parks and Wetlands.

- It has remarkable cultural resources such as archaeological sites and World Heritage Sites, such as the Parthenon, the Temple of Poseidon (Sounio), the Temple of Amphaeus (Aegina), and even world-class museums such as the Acropolis Museum. Most of and important cultural sites are located in the central area of Athens, which includes 38 monuments, 32 archaeological sites, 28 state museums and 30 nonpublic museums [4].

- It includes many sports facilities and Olympic works that were created to serve the Olympic Games of 2004.

- The region includes the largest airport in the country, Elepherios Venizelos that give to Attica the primary national and international air hub of Greece. In addtion to this, it includes four ports of National Importance (Piraeus, Elefsina, Rafina and Lavrion) linked to the Trans-European Transport Network.

- Urban tourism due to cultural resources and marine tourism in coastal areas is highly flourished.

- It presents intense growth of coastal areas with a driving force on residential and tourist development.

\subsection{Tourism Development}

Many coastal areas of the Attica were originally rural. After 1928 these areas received refugees from Asia Minor and started to develop [5]. Also, the degradation of the areas of the center of Athens, the search for a better quality of life and good climatic conditions, led residents to look for areas of second residence.

Thus, the areas not originally developed were second-dwelling areas, while at the same time tourist accommodation was establised. These areas of the second residence, evolved into settlements of permanent residence and then into urban areas. This had as a result the appearance of high-quality tourist accommodation in urban areas such as the Vouliagmeni area.

Also, with the conduct of the Olympic Games, various projects were carried out to promote cultural resources such as (redevelopment of the Plaka area, interventions for the unification of the Archaeological Sites and other). These projects have enhanced the potential of tourism development. However, Olympic facilities have not been sufficiently exploited to contribute to the development of tourism [4].

\subsection{Tourist Facilities}

As it is explained above the tourism in the Attica Region is geared to historical-cultural tourism (the city's world-wide monuments) and to tourism for marine recreation in coastal areas. While there is a lack of planning of major events to prolong tourism throughout a year. The hotel potential in the region of Attica is:

TABLE 1: Hotel Potential in the Area of Attica [6]

\begin{tabular}{lllllll}
\hline Attica & Category & & & & Total \\
\hline & $5^{* * * * *}$ & $4^{* * * *}$ & $3^{* * *}$ & $2^{* *}$ & $1^{*}$ & \\
\hline Hotel units & 34 & 103 & 136 & 267 & 109 & 649 \\
\hline Rooms & 6603 & 8133 & 6698 & 8183 & 2084 & 31701 \\
\hline Beds & 12565 & 15203 & 12257 & 15062 & 3935 & 59022 \\
\hline
\end{tabular}

\subsection{Tourist Movement}

According to the statistical data, in the Attica region it is found out that in the period of 2000-2004 the number of arrivals of tourists presents a decrease but it increases in the following years until 2007. Then, the arrivals keep steady until 2011. In 2012, the arrivals decline slightly, following by a gradual increase until 2015 , which remains slightly the same in 2016 (Fig 2). In addition, it is found out that the number of arrivals of natives 
drops only slightly during 2000-2004, while it increases during 2005-2009. In 2010 the arrivals drop dramatically which continues until 2016. In contrast, the number of foreign tourists has been on a downward path from 2000 to 2005 and then it increases until 2016.

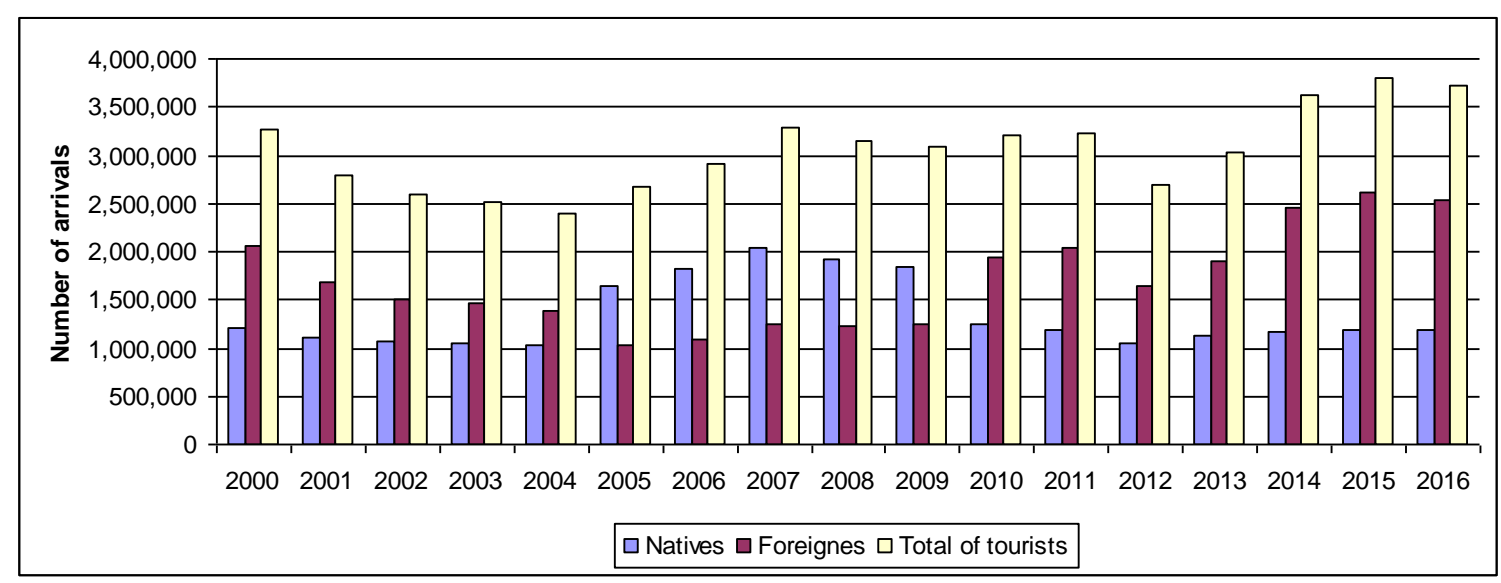

Fig. 2: Number of arrivals in the area of Attica from 2000 to 2016 [7]

A similar pattern of arrivals follows the number of overnight stays. During the period 2000-2003, the number of overnight stays is gradually decreasing until 2003, while in 2004 there is an increase until 2007. During the period 2008-2011, the overnight kept the same rate. In 2012 it is found a slightly decreased in overnight stays, which it is followed by an upward trend until 2016. The overnight stays of foreigners outweigh the number of natives, with the exception of the period 2005-2009, where the natives are outweighed (Fig 3).

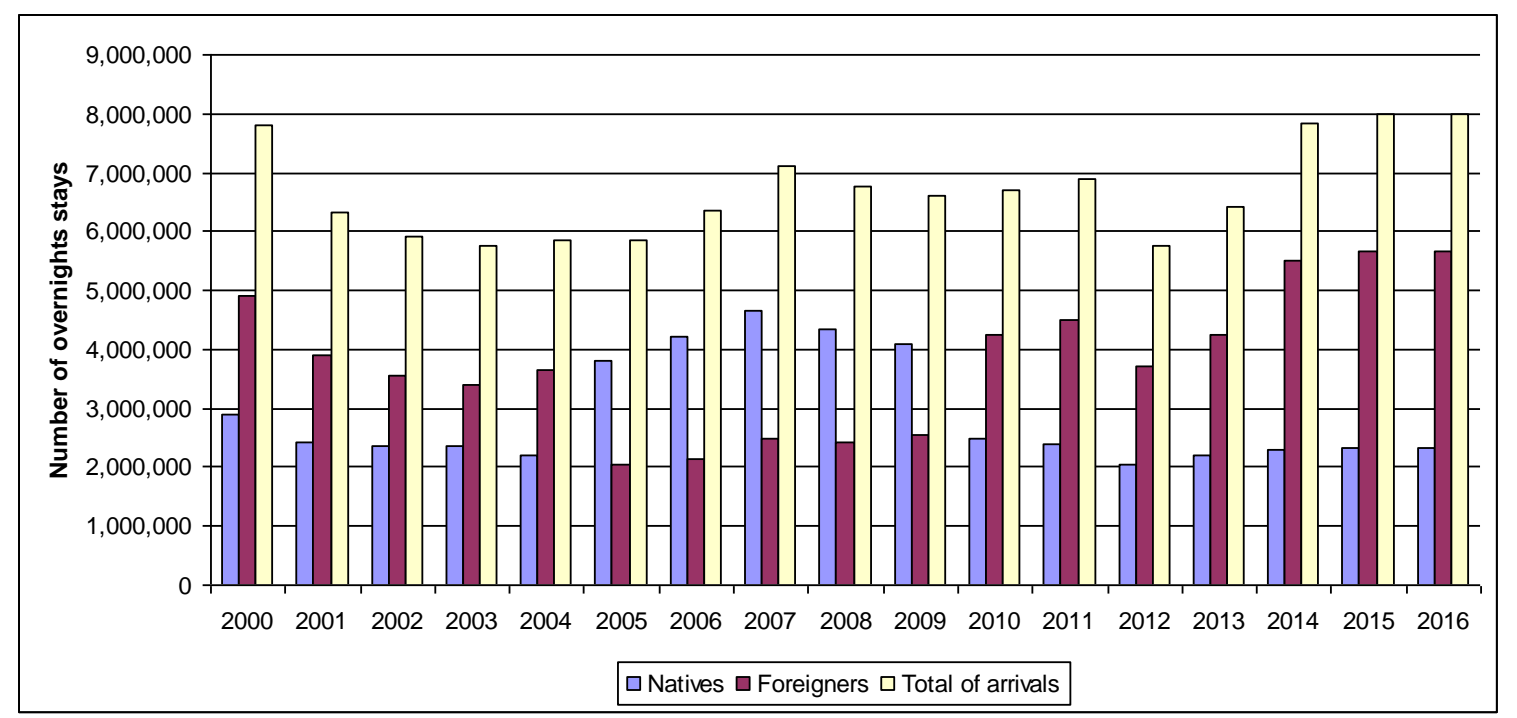

Fig 3. Number of Overnight Stays in the Area of Attica from 2000 to 2016 [8]

Taking into account the area of tourists' stay, it is found that the majority of tourists prefer to stay in the downtown in the area of Athens, in the areas of the big means of transportation such as, Eleftherios Venizelos Airport, Piraeus port, Lavrion port and coastal urban areas of Attica that have hotel units as well as on islands that are tourist destinations due to the remarkable natural resources that have.

\subsection{Cultural Movement}

In the region of Attica, cultural monuments, museums and archaeological sites are centers of attraction of tourists. The largest number of visitors are interested in the museums of Athens, particullary the Acropolis Museum (1,406,096 visitors), the National Archaeological Museum (447,093 visitors), the Benaki Museum 
(98,329 visitors), the Byzantine and Christian museum of Athens (72,279 visitors), the National Picture Gallery - Al. Soutzou museum (31,083 visitors), the Numismatic museum (20,064 visitors), the National Archaeological museum (17,763 visitors), the Museum of Kessariani Monastery (17,261 visitors), the museum of popular art (11,632 visitors), and the Pireas Archaeological museum (10,474 visitors). Here are the museums with less visitors than 10,000 such as the Epigraphical Museum of Athens, Canellopoulos Museum, Poros museum, Lavrio museum, Megara Archaeological Museum and Kythira Byzantine museum [8].

\subsection{Problems in Municipalities of Attica}

The environment of Attica faces various problems related to the evolution of the residential network over time and the expansion of the Region's Urban blocks.

In the framework of the survey, a sample survey was carried out in coastal municipalities that shows strong urban development and tourism potential from the Municipality of Moschato-Tavros to the Municipality of Varis-Voulas-Vouliagmenis. Thus, a research in situ and interviews with the competent staff of the Coastal Municipalities were carried out. The aim of the survey was to identify the various problems of the Municipalities, how they were dealt with and how they are related to tourism development. The survey has shown that:

Coastal Municipalities face many problems that have to do mostly with urban development and less with tourism development. Specifically:

- Areas are under pressures for expansion of buildings and pressures due to land uses intensity.

- Traffic problems, noise pollution, lack of parking space.

- Noise pollution from the seafront entertainment centers.

- Waste management problems due to the lack of waste concentrations centers.

- In some areas there is not a flood defense network (Municipallity of Alimos and municipality of Glyfada).

- Involvement of many bodies for coastal zone management

- Incompatible land uses in the coastal area.

- The coastal road has cut off the urban fabric from the coastal area.

- Marine pollution problems from the passage of Ships and pleasure yachts.

Regarding in tourist development, coastal municipalities have different hotel potential and therefore different impacts from tourist movement. The areas Municipality of Moschato_Tavros the Municipality of Kallithea and the Municipality of Elliniko-Argiroupoli, which are not tourist areas, has few hotel units.

The area of Mochato presents low quality hotel units (1 hotel unit of D category and 6 hotels units of C category) with a small number of overnight stays. Similarly, the Municipality of Kallithea has 2 hotel units of C category and the Municipality of Elliniko-Argyroupoli has 1 hotel unit of E category.

Other regions have a medium-sized hotel potential such as Palaio Faliro 6 hotel units, 2 A, 1 B, 2 C and 1 D of category), Alimos (8 hotel units, $7 \mathrm{C}$ and $1 \mathrm{~A}$ of category).

In contrast, the Municipalities of Glyfada and Varis-Voulas-Vouliagmenis present high-quality hotel potential. The Municipality of Glyfada includes 18 hotel units (5A, 10B, 3C), and the Municipality of VarisVoulas-Vouliagmenis includes 24 hotel units (Voula 6 hotel units (2B, 3C and 1D), Vouliagmeni 12 hotel units (7A, 1 B and 1 C) and Vari 6 hotel units) [4].

In addition to the climatic conditions and the valuable natural resources, Glyfada is also a recreation center. Also its proximity to the former airport of Elliniko, had resulted in developing of hotel units. While, tourism development in Vouliagmeni was strengthened because of it had the remarkable natural resources such as long coastlines, a large percentage of green areas, and others [4].

These areas face problems of management and better utilization of the beaches (such as the areas of Elliniko and Voula). 


\subsection{Projects for Tourism and Development}

Various projects and actions have been carried out in the region of Attica for the region development (Table 2). During the period time 2007-2013, most of the project budget is the development of human resources and entrepreneurship, clean urban transport, lifelong learning and environmental actions. While tourism and culture occupy low rates of $0.25 \%$ and $3.28 \%$ respectively.

Tourism projects concerned the promotion of natural resources, the protection and development of the natural heritage and finally the improvement of tourist services. While cultural projects concerned the protection and preservation of cultural heritage, the development of cultural infrastructure and contributions to the improvement of cultural services.

While environmental projects are concerned for soil, air, water, climate change mitigation, biodiversity promotion, risk prevention and waste management.

It is noted that new projects and actions have been included in the new NSRF 2014-2020 for the further development of the Attica region.

TABLE 2: Approved Projects and Actions Per Sector During the Period 2007-2013 [9].

\begin{tabular}{lcc}
\hline NSRF 2007-2013 & Project Budget (Euro) & $\%$ \\
\hline Human Resource Development & 809856653 & 16.46 \\
\hline Entrepreneurship & 769138820 & 15.63 \\
\hline Clean Urban Transportation & 676232507 & 13.74 \\
\hline Education and Lifelong Learning & 641260133 & 13.03 \\
\hline Environment Activities & 454850712 & 9.24 \\
\hline Transport & 392220404 & 7.97 \\
\hline Research \& Technology & 265145876 & 5.39 \\
\hline Urban regeneration & 181790990 & 3.69 \\
\hline Energy & 162583498 & 3.30 \\
\hline Culture & 161577056 & 3.28 \\
\hline Digital Convergence & 151646388 & 3.08 \\
\hline Health and Social Care & 142556564 & 2.90 \\
\hline Technical Support for Implementation & 72706840 & 1.48 \\
\hline Public Administration Reform & 15180240 & 0.31 \\
\hline Tourism & 12484229 & 0.25 \\
\hline Shipping & 11289381 & 0.23 \\
\hline Total & 4920520291 & 100.00 \\
\hline
\end{tabular}

\subsection{Impacts from Tourism Development}

In the tourism sections, Attica has a reduced attractiveness as a tourist destination. Athens has not managed to capitalize on the organization of the Olympic Games for the development of tourism.

After the Olympic season, there was an increase in tourism, which was mainly due to the increase of native tourists. However, the economic crisis since 2009 and then has influenced the length of overnight of natives, while on the contrary it has been increased the number of foreign tourists.

The biggest movement is noticed in the area of Athens, due to the remarkable cultural heritage monuments and in the areas that have high hotel potential in combination with and the remarkable natural resources.

Tourism in the Athens area due to cultural resources has contributed positively to the economy (income from visits), in the increasing of employment in the tertiary sector, in keeping maintenance of archaeological sites and in the promotion of cultural heritage.

Similarly, tourism development in the coas tal areas of Attica, on one hand, has contributed to the economy of these areas, on the other it threatens with degradation the quality of their natural resources. Such as, alteration of the environment, the natural landscape and aesthetic degradation due to the construction of large blocks of flats near the sea. Noise problems due to increasing traffic, the large numbers of tourists and leisure facilities, increasing building and phenomena of land use conflicts. 
Areas with a high hotel potential accept the greatest consequences.

Attica islands due to its limited extent presents important particularities. Sufficient resources are needed to cover the necessary infrastructure such as sewage treatment plants. While the local community is more sensitive to the impacts which receives from the tourism. In addition to this, the residents of the host areas are trying to adapt to the preferences of tourists, resulting in the commercial exploitation of the tradition and the cultural dependence of the host country on the classic type of "Western culture".

Also, the marine space of the Attica, faces pollution problems caused by the passage of ships and pleasure boats.

\subsection{Measures to Address Environmental Problems}

The proposed measures to address the problems in the study area are:

- Implement law decrees in order to regulate land use and restrict building

- Traffic regulations and measures for noise pollution.

- Connection of the coastal front with the urban fabric (underground passages)

- Exploitation of coastal space. Better exploitation of beaches, protection from arbitrary construction, cleanliness and development other maritime activities.

- Strengthening tourist development such as upgrading hotels units to provide high quality services.

- Creation of other sewage treatment plants for areas that do not have any sewage treatment plant as they are necessary to protect water from pollution.

- Measures to strengthen urban tourism.

\section{Conclusions}

The Attica region has remarkable natural and cultural resources that attract tourists. These natural resources, although under protection, are now threatened by degradation from the intensity of land uses.

Various projects such as the construction of Olympic projects, projects for the upgrading of areas and the development of transport have contributed greatly to improving the quality life of both residents and tourists.

At the same time other projects have been too funded, such as upgrading of areas, promotion of archaeological sites and others. The funding from the community support frameworks has largely contributed to this development.

Despite the economic crisis since 2009 and then which has affected all sectors with a recession, an increase in tourism has been made due mainly to foreign tourists.

However, the economic crisis has led to major changes in the region of Attica, such as population's movements for job search, the increase in the unemployment rate, the decrease of the income, and others. Thus, due to the economic situation, new economic development initiatives are being sought, such as the strengthening of tourism development. Taking into account, the remarkable cultural resources, the region has a possibly develop winter urban tourism. Of course, apart from everything else, hotel accommodation should be upgraded in order to provide high quality services.

It is not only the contribution of the residents of the area but also every European citizen should support and enforced this hard work to protect the cultural monuments, for a place which has contributed so much to culture and has influenced political and scientific thinking in a global level.

\section{References}

[1] EC (European Commission). European Commission Communication Europe 2000, Brussels, 1991.

[2] UNEP/MAP/PAP. "Guidelines for an environment approach to the Planning and management of tourism Development in Metiterranean Coastal Zones Priority Actions Programme", Regional Activity Centre, SPLIT, 1989. 
[3] HNMS (Hellenic National Meteorological Service). Meteorological data of weather station in the area of Elliniko. Athens, 2012.

[4] Economou A. "Urban environment in the coastal area in the region of Attica and European policies", Post-doctoral research, National Technical University of Athens, 2013, pp. 1-237.

[5] HSAG (Hellenic Statistical Authority of Greece). Statistical data: Demographic data: Population and Housing cencus 1920-2011 in Greece. Athens, 2012.

[6] HSAG (Hellenic Statistical Authority of Greece). Hotel Potential in the area of Attica, 2017.

[7] HSAG (Hellenic Statistical Authority of Greece). Statistical data: Tourism movement in Greece.2017.

[8] HSAG (Hellenic Statistical Authority of Greece). Statistical Data: Admissions to museums by month in Attica,2017.

[9] MFIST (Ministry of Finance, Infrastructure, Shipping and Tourism). Statistical data:Approved projects in National Strategic Reference Framework (NSRF) 2007-2013 in Greece,Athens, MFIST, 2015.

(http://anaptyxi.gov.gr/). 